\title{
POTENTIALITIES AND LIMITATIONS OF NETWORK ANALYSIS METHODOLOGIES: A THEORETICAL MODEL FOCUSED ON THE Social Sciences
}

\author{
Francisco Conrado Filho \& Luís António Santos
}

\begin{abstract}
This paper explores the potentialities and limitations of network analysis, not only as a methodological tool that may be used in Social Science research but also as a separate discipline, with its own well-tested theories. Providing a framework for the use of network analysis involves discussing the role that it can play in understanding objects using a field that is sometimes accused of being too technical. Despite the fact that it has increased in popularity over recent years, driven by new communication technologies and especially social media channels, network analysis has a much broader use, and we therefore aim to demonstrate some innovative approaches that may be used in Social Science research. Finally, because it is an interdisciplinary methodology, we discuss some of the associated risks and biases.
\end{abstract}

KEYwORDS

Methodologies; network analysis; social media; Social Sciences

\begin{abstract}
RESUMO
Este artigo procura discutir o lugar da análise de rede dentro das Ciências Sociais, não somente como uma simples ferramenta de investigação metodológica, mas também na perspetiva de um campo de investigação com teorias próprias e consolidadas. Enquadrar a sua utilização significa discutir o seu papel na análise e compreensão de objetos por um campo que sofre, às vezes, acusações de ser bastante tecnicista. Apesar de impulsionado pelas novas tecnologias de comunicação e pelos média sociais, em particular, a análise de rede tem um espectro de utilização muito mais alargado, pelo que pretendemos apresentar algumas das abordagens possíveis na investigação em Ciências Sociais. Por último, tratando-se de uma metodologia interdisciplinar por natureza, acautelamos alguns dos seus riscos e enviesamentos.
\end{abstract}

Palavras-chave

Análise de rede; Ciências Sociais; média sociais; metodologias

\section{INTRODUCTION}

New times bring new challenges and in their wake new research methodologies are created, restructured or simply resumed, in an attempt to explain specific realities. Network analysis methodology is yet another example of reappropriation of existing tools to explain new contexts, that has grown and created its own field of investigation. It is by no means a recent methodology, since network analysis conquered its status as a mature 
field of enquiry in the 1970s. However, it has only been over the last decade that its reach has grown exponentially, used by researchers from a wide range of fields, largely due to two fundamental factors: access to the tools and major popularisation of the concept of networks. This can be deduced from Watts' defence of what is now known as the "science of networks":

spurred by the rapidly growing availability of cheap yet powerful computers and large-scale electronic datasets, researchers from the mathematical, biological, and social sciences have made substantial progress on a number of previously intractable problems, reformulating old ideas, introducing new techniques, and uncovering connections between what had seemed to be quite different problems. The result has been called the "new science of networks". (2004, p. 243)

For the purposes of this paper what mainly interests us is to focus on the concept of the network and its application within the field of the Social Sciences. We will try to demonstrate that network analysis is not merely a descriptive and quantitative tool. To this end, we will retrieve concepts from the recently formulated Network Science.

Anyone looking at all the currently available range of network analysis tools, many of which are suited for studying social media, may gain the impression that this is a field closer to the Exact Sciences than the Social Sciences. This is an understandable mistake, but since we don't aim herein to look at the history of network analysis, it's important to remember that this methodology was born in the context of Sociology and Anthropology, and has always been used by these fields of knowledge to explain the intricate web of relationships and social influences between specific actors and institutions. Despite its appearance to the contrary, the methodology of network analysis is closely linked to the Social Sciences. That is why we are interested in discussing its role and value.

It's also important to point out that when we refer to Network Analysis, in its broad sense, rather than using the more common term, Social Network Analysis, this is because we aim to avoid the ambiguity that this term generates with the concept of "social networks" in Portuguese. The aforementioned social networks may be online networks and also those based on observed experience of daily life. The explanation for this technicist view of the concept of networks primarily derives from the fact that when speaking about social networks, many people are led to believe that we are talking about platforms such as Facebook, Twitter, Instagram and, for this reason, attribute a more technologyoriented connotation, than that which the term actually indicates. To avoid such ambiguities, when referring to online social networks, we will use the term social media. Among other reasons, this is the most appropriate term to explain the role played by these platforms in media consumption. Not only do they fulfil the function of creating social bonds between users, they are also used for parallel activities (Amaral, 2012). For a better understanding of this concept, Fuchs stated:

social media is a complex term which involves different layers. Facebook contains a lot of content (information) and is also a tool for communication 
and for the maintenance and creation of communities. It is only to a lesser extent a collaborative work tool, but involves at least three types of sociability: cognition, communication, and community. (2014, p. 6)

Having made this clarification, and prior to analysing networks in greater detail, we must first clarify the concept in question and discuss precisely what networks represent.

\section{SOCIAL NETWORK: A CONCEPT}

Network, can ultimately be understood as the context, i.e. the entire social structure that brings together actors and institutions who contribute, compete, or otherwise converge towards the events that are being observed. Wasserman and Faust (1994) argue that, from a network perspective, society as a whole may be expressed as a set of patterns and regularities observed in the behaviour of its individuals. The term network therefore opens space for a large number of distinct representations of reality. This is clear in Serrat's description:

social networks are nodes of individuals, groups, organizations, and related systems that tie in one or more types of interdependencies: these include shared values, visions, and ideas; social contacts; kinship; conflict; financial exchanges; trade; joint membership in organizations; and group participation in events, among numerous other aspects of human relationships. (2017, p. 39)

For Molina (2009), the term network is the perfect metaphorical representation of the complexity surrounding social actors. Therefore, its visual representation is not only obligatory, it also offers a link between the metaphor and the concept studied. From this perspective, it is not difficult to see that all individuals belong to networks of influence, regardless of whether they are conscious of this fact, and their actions can be better understood by analysing their relationships within the network to which they belong, rather than via their individual attributes.

The emphasis placed on the dynamics of relationships is nothing new. In the nineteenth century, Emile Durkheim, one of the founding figures of Sociology, conceived of societies as biological systems, which as such could be studied using the pattern of relationships that originated within them (Borgatti, Mehra \& Labianca, 2009). These regularities should be understood as the structures that may enable individual action and, consequently, the study of individuals' attributes should be understood by the structure in which they are inserted.

What seemed only to be an intuitive metaphor was formalised decades later through the incorporation of elements from Graph Theory. The morphological characteristics of networks then began to be identified and it was established that these are intrinsically related to the behaviour of the individuals integrated within these networks (Lemieux \& Ouimet, 2012). 
Moreno is considered to be the first person to have conceived the idea of applying the study of networks to explain individual behaviour, in what later became known as sociometry: a technique that is used to graphically visualise the ties, even if subjective, between actors (Moreno, 1934). Since then, this field has flourished through the incorporation of matrixes, from the aforementioned graph theory, as well as concepts from the fields of Psychology and Sociology.

In the wake of these incorporations, that which previously had been solely conceived as a methodology - inasmuch that it established a set of procedures for analysis of a specific object - came to be recognized as a theoretical perspective with its own distinct formulations, concepts and theories. The work of authors such as Watts and Strogatz (1998) was important in formulating the concept of dynamic networks, given that they stated that networks do not present ordered or random behaviour, but instead exhibit important properties of the two concepts, wherein these properties are extrapolated using relatively simple mathematical models. Another key work that refounded the vision of networks was by Barabási and Albert (1999) who proposed scale-free models and preferential attachment between actors, that came to be known as the power law. These essentially mathematical concepts quickly gained adepts within the field of the Social Sciences. For example, the power law argues that networks evolve on the basis of principles of preferential attachment, i.e. following the logic that just as a rich person gets richer and richer, more popular nodes tend to attract more attachments than others. Applied to the Social Sciences, we find a direct connection with the concept of "social capital" (which we will discuss in greater detail below).

It is these principles shared across a wide variety of different systems that has led various authors to affirm that a new theoretical perspective is being developed (Barabási, 2002; Buchanan, 2002; Watts, 2003). This perspective is not confined solely to the study of mathematical objects, but also of biological organisms and social organisations. This idea, as we have already shown, dates back to Durkheim.

Barabási (2016) goes on to say that the key to discovering Network Science arises from the fact that network architecture - which has emerged in a widely diverse array of scientific fields - proves that networks are governed by the same organising principles and, therefore, are likely to share the same mathematical exploration tools.

In light of the above, we can conclude that the term network can be used to describe indigenous communities, urban households, online sharing platforms, as well as electrical installations and national railway systems. It is precisely the malleability of the concept that has endowed the idea of network analysis with an interdisciplinary vocation. The easy graphic representation, using points and lines, enables it to be used in highly diverse systems: for a social actor, an institution, bacteria, or a railway station. Furthermore these elements may be converted into more generic categories, which will be discussed later in this paper.

As a consequence, the network perspective can be applied whenever there is a relationship of interdependence between the analysed objects. The question becomes even more relevant when we leave the field of mathematical applications and work on 
the theoretical perspectives underlying construction of a network, such as the construction of identities, principles of transitivity, homophilia, structural holes, and small world theory, etc.

\section{SOCIAL NETWORK: A PERSPECTIVE}

Regardless of the possible discussion as to whether the network perspective is merely a methodology that aims to become a new field of knowledge, certain elements help us realise that this involves more than just an elaborate set of techniques for analysing a specific phenomenon. Borgatti, Mehra and Labianca (2009) identify the fact that these criticisms are nothing new, and are based on two points: the absence of its own theories and assuming an essentially descriptive nature.

The accusation that network analysis lacks its own native theories is not only erroneous it also fails to recognise the crucial role played by many of these theories in explaining various phenomena. Furthermore, the fact that network analysis borrows theories and concepts from other fields ultimately demonstrates its trans-disciplinary role and therefore recognises the existence of fundamental principles rooted in a wide range of different fields of research. Furthermore, science has always functioned as a catalyst for the most diverse forms of knowledge. Given that we are focusing on the Social Sciences, we will mention some of the transversal theories that help demonstrate that the network perspective can be applied to other contexts.

\section{CONSTRUCTION OF IDENTITIES}

The power of alterity is the concept used by sociologists such as Viveiros de Castro (2002) and Stuart Hall (2000) to describe the process of constructing identity through direct contact with the other. Notions of subjectivity emerge when we are faced with different perspectives. This is how the identities of peoples and nations are socially constructed (Ashmore, Jussim \& Wilder, 2001). Viveiros de Castro seeks to explain his concept using the example of the question of self within communities by stating: "if I think, then I'm also the other" (2010, p. 117).

What the authors clearly seek to assert is that there is a web of relationships created by the individual as he seeks to define his identity. Given that which we stated earlier that any relationship of interdependence can be analysed as a network - in the final instance, we are stating that network analysis not only enables us to understand a specific phenomenon, but also, and this is the conclusion of the line of reasoning commenced above, it permits analysis of the construction of the identities of its participants. To the extent that the basic unit of network analysis is the dyad (i.e. the connection between at least two individuals), the construction of identities occurs in a negotiation of values between actors within a given network. This network can be described using the principles of Network Science.

It is important to emphasise that complementarity of methods is ideal in a research project of this scope. Indeed, the concepts used to explain social dynamics will also be 
the same as those used to understand the regularities found in networks such as Barabási's power law (1999) or the dynamic and unstable character of networks defended by Watts and Strogatz (1998).

\section{SOCIAL CAPITAL}

Another example of this is the manner in which influence follows a pattern that may be described in the form of a network. Foucault (2004) discussed the microphysics of power, but made it clear that this web of influences is jointly interwoven and never occurs in a vacuum. Social power today does not reside solely in individuals or in democratic institutions, but also in the structure that underpins society as a whole. To understand this phenomenon, we can adopt two different focuses: using network analysis to try to understand the relationships between the actors of this network or to seek correlations between the attributive characteristics of each of the actors, in an attempt to explain their actions.

We mention power relations and influences, because these are two concepts that cannot be forgotten when we look at a social network and try to understand it. Many studies have tried to answer the question of knowing how influence is demonstrated in networks (Huffaker, 2010; Meyerowitz, 1999), whether through the social capital acquired by certain actors (Bourdieu, 1986) or through the construction of imagined "sharing communities" (Anderson, 1991), or also via the forces of weak ties (Granovetter, 1983). The latter aspect is identified as one of the main theories underpinning the network perspective.

\section{THEORY OF THE STRENGTH OF WEAK TIES}

An example of a distinct approach to network analysis in relation to more traditional social science methodologies is related to how networks are built and evolve over time. Granovetter (1983) argued that strong social ties result in redundancy of information circulating within a specific group or community and therefore foster the stability of the network. However, knowing that networks are dynamic, we can find changes in the initial structure of a community when new information is brought into that group. This information is usually passed via those with weaker ties, i.e. those who are known not to share the same level of mutual knowledge of the other members. In network analysis, this concept found expression in the theory that the people with whom one is connected and the intensity of these connections are decisive in the access to different resources. The intensity of connections as well as their directionality are two native concepts of network analysis.

\section{Structural holes}

The structural hole is another important theory that led to formulation of a set of concepts such as the centrality and position of the actor within a network. If in a specific 
network of three members, two of these members have no direct link between each other, then they will be dependent on the betweenness of a third member. According to Burt (1987) this means that we are facing a structural hole. Structural holes and the strength of weak ties, are important concepts that help explain the development of a network. In an attempt to calculate such approaches, Freeman (1979) has developed several measurements of centrality such as measurement of degree, betweenness and proximity, which translate these concepts into network analysis.

The need for metrics to characterize certain actors is often presented as being negative in various arguments that converge on one point - we are faced with tools of purely quantitative interest. While it is true that we will be quantifying the relationships found within a specific community, what ultimately interests the researcher is to perceive the dynamics involved therein.

We can conclude that using network analysis to explain a phenomenon causes the researcher to assume some $a$ priori theoretical perspectives. These are perspectives that cannot be ignored when reading the data and represent a brief summary of what has been discussed above:

1. All relational data can be translated into a network, given that networks are structures of interdependencies (Wasserman \& Faust, 1994).

2. All human social organization is based on previously established structural networks (Durkheim, 1996).

3. Due to social influences, networks are never static. We are working with temporary portraits of a specific event. Influences translate into power dynamics (Barabási \& Albert, 1999; Watts \& Strogatz, 1998).

4. Social capital may be the main element that explains the power relations that exist within certain communities (Recuero, 2009; Wellman, Hasse, Witte \& Hampton, 2001).

5. Finally, it is worth emphasizing that the behaviour of certain groups will always be the sum of the aforementioned factors (Watts, 2009).

In an earlier study, we proposed that social interaction assumes the form of a fractal (Conrado Filho \& Santos, 2015), but we now realise that the fractal is nothing more than a rather complex way of structuring a specific network. Regardless of the format that this structure may have (fractal, spiral, or a simple organization chart), we will always describe the behaviour of individuals as a network of connections, inclusively because the format of a network is only incidental to its dynamics at the time when the data is collected.

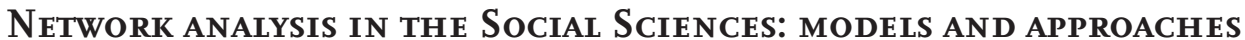

Having discussed the concepts and several existing perspectives of networks, it is important to understand how these may be operationalised in the framework of a research project using network analysis. Fir and foremost, it is necessary to accertain how this network will be interpreted, i.e. whether there will be consideration of the network as a whole or just the personal position of a specific actor (or as we will call it here, ego). 
Molina (2009) proposes to divide these two views between models based on structuralist and formalist approaches. We don't use the same nomenclature, but nonetheless share the underlying idea, since both terminologies, in theoretical terms, lead to conceptual overlaps. For this purpose, we only need to use the definition of structuralism, as advocated by Lévi-Strauss (1949), who said that the concept of social structure is associated with universal notions or categories of culture and linguistics. In other words, not atomism, but instead understanding relations as a totality rather than in terms of the individual parts. In this sense, the form of a structure assumes a preponderant role over its constituent elements.

Formalism is associated with the arts, mathematics, and philosophy, which emphasise form over content (Erlich, 1973). Ultimately, observing the structure and form of a network involves overlapping concepts and is therefore redundant.

Due to this divergence, we have adopted the terms macro or socio-centred, and micro or ego-centred, to indicate formalists and structuralists, respectively, in the context of network analysis. Ultimately, our divergence with Molina is primarily related to form rather than content, since we agree with the definitions of both the approach models presented herein.

\section{MACRO APPROACH MODEL (SOCIO-CENTRED)}

In the macro or socio-centred approach, emphasis is placed on the totality, rather than the individual actors pertaining to the network. Garton, Haythornwaite, and Wellman provide a more accurate description, by stating that macro approaches

considers a whole network based on some specific criterion of population boundaries such as a formal organization, department, club or kinship group. This approach considers both the occurrence and non-occurrence of relations among all members of a population. A whole network describes the ties that all members of a population maintain with all others in that group. $\left(2006, \int 20\right)$.

In practical terms, this means that when looking at a community, it is in the interests of the researcher to take into account the community as a whole and calculate the centrality measures of the entire network.

One of the important aspects of network analysis is to gauge how densely connected a specific community is. This measure can only be calculated if the whole group is taken as a reference. In this manner, it is possible to identify structural holes and actors who have dominant positions (which according to Lemieux and Ouimet (2012), can be dominant, semi-dominant, subdominant, dominated, sub-dominate and isolated).

It is important to note that these interpretations only make sense when there is interest in understanding the network as a whole. A very common example in the field of communication science is analysis of social media data, such as Twitter. When interpreting data from the events of this network, it is extremely important to identify which 
actors stood out within this network and influenced its dynamics. This type of reading can only be performed if we adopt a macro perspective, wherein the relative importance of a specific actor is directly related to his position within the network.

Another way of conceiving an explanation for a socio-centred approach is through the centrality measures. One of the most immediate ways to approach a database is to look for the prominent members in the network using centrality measures (e.g. betweenness, closeness and eigenvector). These measures indicate the actors with greatest prominence in a specific function. Barabási (2016) affirms that it is not difficult to realize that not all actors have the same prominence in a network. The advantage of this approach is that it reveals which actors occupy privileged positions within a structure and thereby point out ways or hypotheses about the way this network works. It is important to emphasize that centrality measures serve to indicate the presence of prominent relationships.

Obviously, when this approach was conceived, automatic data collection tools were not yet available, such as scripts which, when used in conjunction with the Application Programming Interface (APIs) of platforms such as Facebook or Twitter, can produce networks with thousands of members simultaneously. These Big Data processes give new meaning and relevance to socio-centric approaches.

\section{MiCRO APPROACH MODEL (EGO-CENTRIC)}

When the interest of research falls on the individual (ego) and the relationships that he develops within a certain network, we are faced with a micro or ego-centric approach. Again, we turn to Garton et al. to define this model:

one approach considers the relations reported by a focal individual. These ego-centered (or "personal") networks provide a Ptolemaic views of their networks from the perspective of the persons (egos) at the centers of their network. Members of the network are defined by their specific relations with ego. (2006, \ 19)

As is clear from the above, this approach focuses on the individual connections of a specific actor and how these relationships help define his behaviour. The other actors in this network are seen as members that help define the ego, not because of their individual attributes, but because of the relationship they establish.

For years this has been the most popular approach because it is more easily constructed. It is largely based on personal reporting that the ego provides of his social ties. In this specific case, for example, there is no need to calculate centrality measures for the whole network given that the only relevant measures are those that are directly established between the ego and the others. In this sense, in the case of egocentric networks there is no interest in knowing whether a relationship exists between the other members of the network. An example of this can be expressed as follows: if $A$ is our ego and $B$ and $C$ are the other members of the network of connections of actor $A, I$ don't care if $B$ and $C$ are connected and what kind of relation they may have. 
In Anthropology, this type of analysis serves to compare different micro networks and then understand their relationship with the perception that its members have of it. The group's real social configuration can be inferred on the basis of this comparison.

The data is collected through direct observation, interviewing or application of surveys to the participants, using a snowball logic.

\section{BLOCK MODELLING}

Block modelling (or limited models) is applied when one wants to collapse a complex network in search of a common denominator. This type of analysis was first developed by Lorrain and White (1971), in an attempt to aggregate actors who had equivalent structural functions within a network. In this approach, one can start from both a micro model or a macro model (more common), the most important thing being the definition of the roles played by each of the actors involved.

In this manner, we interpret the network not as a set of individual actors, but rather as a set of roles that are performed to ensure maintenance of the network. The basic unit of analysis ceases to be the ego and instead becomes the set of actors who perform similar functions.

It is a well-documented fact that actors who play similar structural roles tend to give very similar responses when confronted with the same kinds of situations (Burt, 1987).

Another way of conceiving block modelling is to partition the network in function of well-defined criteria. It is important to distinguish between block modelling by equivalent structures, as mentioned above, and block modelling by regular equivalence. According to Doreian, Batagelj and Ferligoj (2005), this type of model encompasses a set of empirical procedures and is based on the notion that units within a network can be grouped as long as they present some equivalence, in terms that are defined a priori. In this manner, we can face the question of equivalences, either as different units that present the same connection pattern with the same actors, or as different units that present the same connection pattern, but with actors who also differ from each other (Faust 1998).

A basic example could be as follows. Within a company, the actors $A, B$ and $C$ are supervisors of a specific department. The department is also composed of actors $D, E$, $F$ and $G$. When partitioning the network into blocks, one of the blocks will have supervisors and the other will have the remaining employees. This is because actors $A, B$ and $C$, although different, establish the same type of relationship with the same actors $D, E$, F and G.

The other way to construct the limited model of this same network would be to imagine different departments, in which each one of the leaders establishes the specified connections with the employees, as described above. Obviously, the heads of the other departments do not maintain direct relations with the same set of employees. Thus, although different, equivalence can still be achieved to the extent that the supervisor-employee relationship will remain the same, regardless of the department to which they belong. It should be clear that when we talk about analysing networks, we may be 
referring to a broad spectrum of typologies and in relation to each it will be possible to adopt different strategies of collection, preparation and framing of the data.

Therefore, the correct framing of the initial question will determine the type of approach or model to be used in interpreting this question. This idea is valid both for studies of online events and also for studies of the forms of organisation of a specific community or group. Having established this concept, it is still necessary to recognise that the only difference will reside in the forms of collecting such data, which in some cases will be automated and in other cases collected manually. The final objective will always be to construct a matrix that makes it possible to use graph theory and network theories to explain the object in question.

\section{LIMITATIONS OF THE ANALYSIS}

One of the main limitations of network analysis commences at the moment of data collection. It is easy to understand how manual collection is accomplished: using questionnaires, interviews or even non-participant observation of a set of actors. Examples include the behaviour of students within a school, influences inside a work office, relations of friendship between musicians from different bands etc.

The advantages of this type of data collection include the reliability of the data, since before being placed in the database, it is verified by the researcher (this is a very common problem for researchers working with hashtags and keywords in social media, for example). Manually-collected data is already practically filtered and ready to be analysed. The main apparent limitation of data, and it is important to underline the word apparent, is the range or depth that manual collection can provide, depending on the size and complexity of the observed network.

It is important to set the limits of the intended data collection at the outset. When we refer to an ego-centric approach, for example, it is easy to fall into the temptation of believing that an exhaustive attempt to fill the entire network of a given individual is an achievable task. If we remember that networks are composed of both direct and indirect links, we realise that the network has unlimited growth potential, and it is therefore up to the researcher to define the depth of the data to be collected to evaluate a specific object.

At the other end of the spectrum we have automatic collections, made via social media. These collections entail a set of different strategies to overcome the same obstacles mentioned above. Having chosen the reality to be observed, it is still necessary to understand the possibilities provided by each platform, and that each platform has its own set of technical limitations. Automatic collection should always be conducted using scripts or applications that enable contact with the API of the platform in question. In addition, these APIs exist to control and limit access to some of the existing data - which could lead us to an exhaustive discussion about who owns the rights to the data that we produce online (Bruns, 2016).

In order to exemplify some of the limitations and advantages of such data collection, we will address the two largest social media platforms: the case of Twitter and Facebook. 
Twitter already has a vast academic presence, with searches conducted via the microblogging service. Some of the advantages of Twitter are that all publications are public by definition, the service itself organises the most relevant themes and enables a certain amount of data to be collected. The main disadvantage results from the fact that its sociodemographic limitation is less representative. As Blank summarizes:

British Twitter users are younger, wealthier, and better educated than other Internet users, who in turn are younger, wealthier, and better educated than the off-line British population. American Twitter users are also younger and wealthier than the rest of the population, but they are not better educated. Twitter users are disproportionately members of elites in both countries. Twitter users also differ from other groups in their online activities and their attitudes. These biases and differences have important implications for research based on Twitter data. (2016, p. 679)

If we take into account contexts such as Portugal, where Twitter has a much smaller audience, compared to other networks such as Facebook, we begin to realize what types of impositions we are placing on our data. Study of this context is not invalidated solely on these grounds, but it is necessary to know the context of the analysis in question before beginning to explain it.

Facebook is the most popular existing social media, with over 2 billion monthly active Facebook users worldwide. For this reason we may be led to believe that it presents the best opportunities for interpreting social contexts. The fact is that, being a platform with a more aggressive (and efficient) business model, it hinders and limits access to data, while claiming to protect the privacy of its users (in 2018 we became all the more aware of the fragility of this argument). While with Twitter we have direct access to the conversation flow, on Facebook we are limited to the public pages and public groups. Even the quality of internal data handling by Facebook seems to constitute a problem, since some advertisers have noticed that the target audience of their ads is being misidentified. This is another example of how technical barriers end up by hampering data collection.

However, automated data collection also suffers from another problem, regardless of the chosen platform: filtering. The majority of data collection in large data sets is based on keywords, often ambiguous, which implies a subsequent work of filtering and "cleaning" the database before analysis.

Another limitation that we can point out, and which is not exactly linked to data collection techniques, concerns the difficulty of making comparisons between networks. Although research in the field of network analysis is founded on mathematical principles, we must be extremely prudent when making comparisons between different networks which, in turn, correspond to different phenomena or structures. A simple example concerns the centrality measures calculated in macro approaches. Given that each value relates to a distinct reality, that which may seem to be a high betweenness value, focusing on only one of the most popular centrality measures used in network analysis, this value may not have the same meaning in a network which has a different density or structure. 
We don't want to affirm that comparisons are unfeasible, but rather that they must be considered within groups or communities that are very similar to each other, as in the case of self-centred networks (micro approach).

\section{Conclusion}

Network analysis can always be used to understand a specific phenomenon or behaviour as well as, from a utilitarian perspective, to understand how resources can be rationalised in an attempt to maximize the efficiency of a network. For example, the latter idea is defended by Rod Meadows (1983) who argues that in order for advertisers to understand the behaviour of their customers, it is important to follow the steps taken by users in their various places, mapping their interactions. This task has become easier with the spread of the internet and digital methods.

Obviously, network analysis does not provide answers for all types of contexts. Kozinets (2010) states that to understand the life experiences of a particular online community, network analysis is insufficient. Instead he proposes the use of netnography techniques. However, for contexts where one intends to analyse how the actors of a given community behave and influence each other, network analysis offers the most appropriate approach, since it is based on relational information that, in the final analysis, can always signify how actors shape or construct their own identities (White, 2014).

The potential that social media has brought to the analysis and understanding of an important part of our social behaviour has led to popularisation and use of this perspective on a large scale. The clear benefits that the network perspective presents includes the possibility of identifying patterns in the behaviour of social structures and, thus, it is possible to predict with some accuracy situations that may arise from it.

Another additional value is the ability to better identify and explore the limits of communication, so as to try to make it more effective and democratically distributed. As Fuchs (2015) argues, the idea that social media have singlehandedly strengthened democracy is a somewhat questionable, insofar as one observes the limits to which they are subject.

Weighing up the pros and cons, it is important to recognise that network analysis (or Network Science, as some authors prefer to call it) has therefore brought a set of mechanisms and tools that enables interpretations that are essential for the Social Sciences and recognition of the flexibility of its use in different contexts further enhances its importance.

Translated by Martin Dale (Formigueiro, Conteúdos Digitais, Lda)

\section{BibliogRAPHIC REFERENCES}

Amaral, I. (2012). Participação em rede: do utilizador ao "consumidor 2.0" e ao "prosumer". Comunicação e Sociedade, 22, 131-147. doi: 10.17231/comsoc.22(2012).1278 
Anderson, B. (1991). Imagined communities: reflections on the origin and spread of nationalism. London: Verso.

Ashmore, R., Jussim, L. \& Wilder, D. (2001). Social identity, intergroup conflict, and conflict reduction. Oxford: Oxford University Press.

Barabási, A.-L. (2002). Linked. Cambridge, Massachusetts: Perseus Publishing.

Barabási, A.-L. (2016). Network science. Cambridge: University Press.

Barabási, A.-L., \& Albert, R. (1999). Emergence of scaling in random networks. Science, 286(5439): $509-512$. doi: $10.1126 /$ science.286.5439.509

Blank, G. (2016). The digital divide among twitter users and its implications for social research. Social Science Computer Review, 35(6), 679-697. doi: 10.1177/0894439316671698

Borgatti, S., Mehra, A., Brass, D. J., \& Labianca, G. (2009). Network analysis in the social sciences. Science, 323(5916), 892-895. doi: 10.1126/science.1165821

Bourdieu, P. (1986). The forms of capital. In J. Richardson (Ed.), Handbook of theory and research for the Sociology of Education (pp. 241-258). New York: Greenwood Press.

Bruns, A. \& Burgess, J. (2016). Methodological innovation in precarious spaces: the case of Twitter. In S. Robert, H. Snee, C. Hine, Y. Morey \& H. Watson (Eds), Digital methods for Social Science (pp. 17-33). London: Palgrave Macmillan.

Buchanan, M. (2002). Nexus: small world and groundbreak science of networks. New York: Norton.

Burt, R. S. (1987). Social contagion and innovation: cohesion versus structural equivalence. American Journal of Sociology, 92, 1287-1335. doi: 10.1086/228667.

Conrado Filho, F. \& Santos, L. A. (2015). Second screen and information: history, definition and clues for the future. Comunicação e Sociedade, 28, 211-227. doi: 10.17231/comsoc.28(2015).2278

Doreian, P., Batagelj, V. \& Ferligoj, A. (2005). Generalized blockmodeling. New York: Cambridge University Press.

Durkheim, E. (1996). O suicídio. Lisboa: Editora Presença.

Erlich, V. (1973). Russian formalism. Journal of the History of Ideas, 34(4), 627-638. doi: 10.2307/2708893

Faust, K. (1988). Comparison of methods for positional analysis: structural and general equivalences. Social Networks, 10, 313-341. doi: 10.1016/0378-8733(88)90002-0

Foucault, M. (2004). Microfísica do poder. Rio de Janeiro: Graal.

Fuchs, C. (2014). Social media: a critical introduction. London: Sage.

Garton, L., Haythornthwaite, C. \& Wellman, B. (1997). Studying online social networks. Journal of ComputerMediated Communication, 3(1), s/p. doi: http://10.1111/j.1083-6101.1997.tbooo62.x

Granovetter, M. (1983). The strength of weak ties: a network theory revisited. Sociological Theory, 1, $201-233$. doi: http://10.3390/soc2020027

Hall, S. (2000). The spectacle of the 'other'. In S. Hall (Ed.), Representation: cultural representations and signifying practices (pp. 236-237). London: Sage. 
Huffaker, D. (2010). Dimensions of leadership and social influence in online communities. Human Communication Research, 36, 593-617. doi: 10.1111/j.1468-2958.2010.01390.x

Kozinets, R. (2010). Netnography. Doing ethnographic research online. Thousand Oaks: Sage Publications.

Lemieux, V. \& Ouimet, M. (2012). Análise estrutural das redes sociais. Lisbon: Instituto Piaget.

Lévy-Strauss, C. (1982). As estruturas elementares de parentesco. Petrópolis: Vozes.

Lorrain, F. \& White, H. C. (2010). Structural equivalence of individuals in social networks. The Journal of Mathematical Sociology, 1(1), 49-80. doi: 10.1080/0022250X.1971.9989788

Meadows, R. (1983). They consume advertising too. Admap, 19, 408-413.

Meyrowitz, J. (1999). Understandings of media. ETC: a review of general semantics, 56(1), 44-52.

Molina, J. L. (2009). Panorama de la investigación en redes sociales. REDES - Revista hispana para el análises de redes sociales, $17(11)$, 235-256. doi: 10.5565/rev/redes.383

Moreno, J. L. (1934). Who shall survive? A new approach to the problem of human interrelations. Washington: Nervous and mental disease Publishing Co.

Recuero, R. (2009). Redes sociais na internet. Porto Alegre: Sulina.

Serrat, O. (2017). Social network analysis. In O. Serrat (Ed.), Knowledge solutions (pp. 39-43). Singapura: Springer. doi: 10.1007/978-981-10-0983-9-9

Viveiros de Castro, E. (2002). A inconstância da alma selvagem - e outros ensaios de antropologia. São Paulo: Cosac \& Naify.

Viveiros de Castro, E. (2010). Encontros. Rio de Janeiro: Beco do Azougue.

Wasserman, S. \& Faust, K. (1994). Social network analysis: methods and applications. Cambridge: Cambridge University Press. doi: 10.1017/CBO9780511815478

Watts, D. \& Strogatz, S. H. (1998). Collective dynamics of 'small-world' networks. Nature, 393, 440-442. doi: $10.1038 / 30918$

Watts, D. (2003). Six degrees: the science of a connected age. New York: Norton.

Watts, D. (2004). The "new" science of networks. Annual Review of Sociology, 30(1), 243-270. doi: 10.1146/ annurev.soc.30.020404.104342

Wellman, B., Haase, A. Q., Witte, J. \& Hampton, K. (2001). Does the internet increase, decrease, or supplement social capital? Social networks, participation, and community commitment. American Behavioral Scientist, 45(3), 436-455. doi: 10.1177/00027640121957286

White, A. (2014). From the private to the public: online identity. In A. White (Ed.), Digital media and society: transforming economics, politics and social practices (pp. 26-42). London: Palgrave Macmillan. doi: $10.1057 / 9781137393630$ 


\section{BIOGRAPHICAL NOTES}

Francisco Conrado Filho has a master's degree in Communication Sciences from the University of Minho, where he is now developing his $\mathrm{PhD}$ project. He has dedicated much of his work to studying the relations between the journalistic profession, and journalism itself, with new technologies. More recently, he has studied the shifts in power relations and dynamics of online communication using Network Analysis. He is a member of the research group MODA - Monitoring Online Discourse Activity.

E-mail: franciscoconradofilho@gmail.com

Address: Communication and Society Research Centre, University of Minho, Campus de Gualtar, 4710-057, Braga - Portugal

Luís António Santos is an Assistant Professor at the University of Minho's Department of Communication Sciences and a researcher at the Communication and Society Research Centre (CECS) since 2000, with interests spanning from journalism and digitization to new sound formats and web regulation. A newspaper and television journalist for 10 years - Jornal de Notícias, Rádio Press/TSF, Diário de Notícias, BBC World Service - he has an MSc in International Politics of Asia and Africa from SOAS - University of London and a PhD in Communication Sciences from the University of Minho, Portugal. He has participated in international research projects on media regulation and new radio formats.

E-mail:d266o@ics.uminho.pt

Address: Communication and Society Research Centre, University of Minho, Campus de Gualtar, 4710-057, Braga - Portugal

* Submitted: 30.11 .2017

* Accepted: 15.03 .2018 